\title{
Digital developments highlighted at summit
}

A prescient overview of digital developments and the way they will impact the way dentistry is delivered was the prime focus of Align Technology's first Growth Summit held in Copenhagen, Denmark in September.

The radical and rapid shift towards a digitally focused healthcare eco-system has opened up a new frontier in the world of dentistry, said the company, hence the focus of the conference on digital developments and their impact on dental trends.

For the conference, 75 leading general dentists converged on the Danish capital to learn from experts within the dental sector and beyond and to experience a summit designed to leverage insights into future technologies for dental healthcare beyond the science of tooth alignment.
The Summit's international speakers offered delegates a broad picture of the dental world of tomorrow and beyond, enlightening them about their future role within it, and inspired them to take a wider view of dentistry, whilst embracing the digital revolution.

There were also forecasts of the innovations to come in the next five years with a look at how Align Technology will continue to shift and shape the dental landscape.

During two thought-provoking days of lectures and workshops, the Growth Summit's speakers explored topics ranging as wide as AI (artificial intelligence), the utilisation of social networks to improve health outcomes, big data, biomechanical measurements, the emotional dental experience and the invaluable use of digital tools to aid patient communication.

The presentations also brought into focus the many adaptations general dentists will need to make, as much in their clinical approach as their communications with patients.

Align Technology's EMEA marketing director for the general dentist channel Jody Carter, said this might include instigating and encouraging a public shift away from the more traditional view of both general dentists and the preventive care messages they share.

The new way will include improved clinician-patient connectivity via internet, wearable devices and social networks, as well as utilising in-clinic technologies.

\section{Global company recognised for improving oral care}

Henry Schein, Inc. has announced that it has been named on FORTUNE's 'Change the World' list, an annual ranking of companies that are doing well by doing good.

Henry Schein was recognised for its efforts to improve the oral health and, by extension, overall health of underserved populations around the world.

The 'Change the World' list recognises companies that have had a positive social impact through activities that are part of their core business strategy. FORTUNE considers a company's measureable social impact, the business results of a company's socially impactful work, the degree of innovation related to that work, and how integral the initiative is to a company's overall strategy.

The company's efforts to improve the oral health of people in need were recognised through three initiatives that the company supports as part of Henry Schein Cares, its global corporate social responsibility programme:

- The Alpha Omega-Henry Schein Cares Holocaust Survivors Oral Health Program - an initiative of Henry Schein and the Alpha Omega International Dental Fraternity to provide free oral health care to Holocaust survivors living in poverty across North America
- Give Kids A Smile - Henry Schein helped the American Dental Association create this programme in 2003, and since then it has provided free oral health care and education to more than 5.5 million children in need across the US. Henry Schein has served as the programme's official professional products sponsor since its inception

- The Global Student Outreach Program - through this initiative, Henry Schein partners with dental schools to improve the oral health in remote and underserved communities around the world while enhancing educational opportunities for the next generation of oral health practitioners.

Stanley Bergman, Chairman of the Board and Chief Executive Officer of Henry Schein, said: 'Since our earliest days, we at Henry Schein have worked to align our strengths as a business with the needs of society, so it is greatly rewarding to be named to FORTUNE's Change the World list. This recognition only serves to reinforce our commitment to improving the health of people in need, and we look forward to 'helping health happen' for years to come.'

The full list can be seen at http://fortune. com/change-the-world/.

\section{Autumn and winter study clubs}

Finding easy ways to stay up to date with the latest news, products and concepts in dental implantology can be difficult, but the ADI Study Clubs provide an ideal solution.

Located across the UK, the events offer a chance to learn and network with peers, without the inconvenience of travelling too far. Upcoming ADI Study Clubs available include:

- Complications in Implant Dentistry - A 46-Year Perspective (1972 to 2018) (John Richardson): Newcastle - 12 November 2018

- Implant Complications (Robert Dyas): Wakefield - 14 November 2018

- Understanding the Significance of Occlusal Function in the Aetiology of Dental Failures and Failure of our Interventions (Rai Ahlowalia): Birmingham - 14 November 2018

- Immediate Placement and Loading - A 10 Year Journey (Abid Faqir): Motherwell - 22 November 2018: East Grinstead 29 November 2018

- Preparing the Implant Sites - Is Socket Preservation the Answer? (Nik Pandya): Winchester - 26 November 2018

- Treatment Planning for the Edentulous Maxilla (Andrew Legg): London -

4 December 2018.

Booking is easy online and registration is free for members but non-members are also welcome. More information is available by visiting www.adi.org.uk/studyclubs. 